\title{
Indigenous Management Practices- A Case Study on Street Vendors
}

\section{Keerthan Raj}

Srinivas Institute of Management Studies, Srinivas University, Mangalore- 575 001, INDIA.

\author{
E-Mail: 2keerthanraj@gmail.com
}

Type of the Paper: Research Case Study.

Type of Review: Peer Reviewed.

Indexed In: OpenAIRE.

DOI: $\underline{\text { http://dx.doi.org/10.5281/zenodo.914458. }}$

Google Scholar Citation: IJCSBE

\section{How to Cite this Paper:}

Keerthan Raj. (2017). Indigenous Management Practices- A Case Study on Street Vendors. International Journal of Case Studies in Business, IT and Education (IJCSBE), 1(2), 29-36. DOI: http://dx.doi.org/10.5281/zenodo.914458.

International Journal of Case Studies in Business, IT and Education (IJCSBE)

A Refereed International Journal of Srinivas University, India.

(c) With Authors.

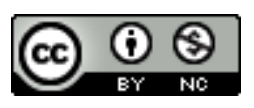

This work is licensed under a Creative Commons Attribution-Non Commercial 4.0 International License subject to proper citation to the publication source of the work.

Disclaimer: The scholarly papers as reviewed and published by the Srinivas Publications (S.P.), India are the views and opinions of their respective authors and are not the views or opinions of the S.P. The S.P. disclaims of any harm or loss caused due to the published content to any party. 


\title{
Indigenous Management Practices- A Case Study on Street Vendors
}

\author{
Keerthan Raj \\ Srinivas Institute of Management Studies, Srinivas University, Mangalore- 575 001, INDIA \\ E-Mail: 2keerthanraj@gmail.com
}

\begin{abstract}
Street vending a very ancient and critical occupation found in each and every country with far reaching economic and social impact. Even before the pre independence era, in India, street vending was by far the only recourse to sales activities in an informal space. Even to this day in smaller semi urban localities and pockets of the country we see a congregation of sellers and buyers getting together in vacant spaces for an informal marketing activity. They are called by various names as in sandy bazaars, santhe's etc which could happen once a week in most places. Not just food, every possible and essential good and in certain cases services are also bought and sold here. While there is a lot of study on formal sales management, marketing mix, product life cycles stages and a plethora of marketing concept, this street vendors business management have been given very little thought and study. In the absence of a shop, any perceivable brand building exercises, advertisements the street vendor is successful in getting very good returns on the minimal capital expenditure invested. This paper is a case study approach to viewing the successful business practices of street vendors. How do these street vendors manage competition amongst them and still continue to attract a growing numbers of customers. Certain sellers have become brands in themselves for certain unique services they offer and able to sustain their product and service through the years successfully. In this paper, we have discussed certain critical practices of street vendors that could be of much use in furthering management theories and practices.
\end{abstract}

Keywords: Business practices, Case study, Street vendor, Management theories.

\section{INTRODUCTION :}

Street vending has for long been a very critical element of the demand and supply chain of the economy of every country. This practice of catering to the needs of buying and selling to the lower class of society (in income and means parameters) has been the topic of much research for the last few years. This informal market segment has been called by various terms such as "subsistence marketplace”, base-of-the-pyramid market", informal segment, unorganised market and so on. The bottom of the pyramid refers to the billions of people living on less than $\$ 2$ per day, as per the definition proposed by C K Prahalad and Stuart L. Hart in 1998 [1]. In India, the situation is still grave, the Rangarajan Committee after re-examining the issue of poverty defined the poverty line in 2011-12 at INR 47.00 (\$ 0.69) per capita per day for urban areas and INR 32.00 (\$0.47) per capita per day in rural areas (June 2016 conversion rate) much less than $\$ 2$ per day [2]. As per the Credit Suisse latest reports, in developed countries about 20 per cent of the population fall in this category. In contrast, more than 90 per cent of the adult population in India close to 90 percent of the population fall in this category [2,3] This is the upper layer of the BoP market, then the lower layer is much lower. Lot of multinational companies such as Procter \& Gamble, DuPont etc failed at serving this market while simultaneously generating a competitive return. The reason being that the high costs of doing business among the very poor demand a high contribution per transaction and this was not possible with the products they took forward to the BoP markets. Several consulting companies have modelled how companies can profit by accessing the bottom of pyramid by utilizing economies of scale. Shampoo sold in small sachets would be a classic example of this and what Unilever has managed to crack in India [1]. 
This paper looks at this model in a bottom up approach. Are there certain sustainable business practices and sales models that have been successful which sellers in this BoP market can practice with tie ups or partnerships with corporate or larger enterprises and move upscale. For one, the street vendor, and the market segment that he has predominantly set up to cater to is a subsistence category.

\section{BACKGROUND :}

This segment of consumers in the subsistence segment is largely characterized by living in substandard housing, having limited or no education, earn minimal incomes, and being unable to afford or even need advanced products and technologies [1,4]. However, lot of evidence across the globe suggests that this conventional thinking has been questioned quite often today. Subsistence consumers and marketplaces can be profitable as well as rewarding to do business with. Subsequent research has shown that BoP consumers are brand conscious as well. Brand influences the new product adoption at the bottom of the Pyramid market . In fact, the mobile phone industry was successful in "cracking the BOP code". The empirical profile of the BoP shown by previous researchers shows some striking patterns of data. More than half of the BoP market spends on food, clothing and healthcare, largely pharmaceuticals. As income rises, the household spending on food declines and the share on transportation, and phone and internet rises sharply. A significant characteristic of this segment is the one to one interaction between these small vendors and consumers, thus counteracting economic and social relationships between buyers and sellers [5]. This socio economic interrelationship has a strong link to sustained market leadership and repeat customers. It creates a strong interdependency amongst the members, thus overtaking the need for and existence of any other form of group influencers or promotions.

Low income individuals overcome the barriers of credit, product sales support and other additional opportunities available to big retailers and wholesalers and create a niche market for themselves wherever they set shop. Street vendors or as called subsistence markets initially were a place of interaction for buyers who wanted essentials and for sellers which the big enterprises or corporations had overlooked or could not serve due to the fact that the return per transaction did not lucrative enough. Over a period of time small sellers found goods or services which could meet their and customers requirements at a low cost with sustained quality and usage effectiveness. Over a period of time large corporations such as Unilever realised the value chain in creating sustainable low cost products that could spread the per transaction cost in such a way that they would stand to profit $[2,5]$. For instance, in India, Hindustan Lever was able to create a water purifier brand for a low cost segment, while the market rested predominantly with only Eureka Forbes and the product price of their product and market penetration strategies were not aimed at the subsistence class of consumers [1,2]. Many markets even today lack a mechanism that links providers of goods and services to low income customer segments. To address this issue, lately, many theorists and researchers have put forward the concept of "micro-franchising" [5-7]. Micro- franchising enables providers of goods and services to reach low income segments by incentivising or contracting local micro-entrepreneurs to cost effectively fulfil a missing function in the value chain, which prevents them from profitably serving these segments, for instance, it could be retailing, marketing or after sales support for this category of customers [5]. Micro-entrepreneurs have a low cost base and understand the local markets and communities that these companies are targeting but might lack required inventory or credit flows [10-12]. By providing this missing link the franchisees can bridge the gap successfully, generate a profit that they can share with the franchisor $[1,13]$. This is a win- win way forward for providers of goods and services in the long run to identify and cater to all segments. However, from the stand point of studying the indigenous business practices of street vendors and what has made them successful, we need to understand the constraints and challenges faced by sellers in the subsistence markets.

\section{CHALLENGES AND CONSTRAINTS OF SELLERS IN SUBSISTENCE MARKETS :}

In order that we better under the business practices that are value additions to sellers in subsistence markets. We need to first look at the deeper constraints and challenges faced by the street vendors, sellers in subsistence markets-

\subsection{Lack of access to credit, working capital and investment credit-}


Subsistence market sellers have always had this constraint of low or nonexistent credit facilities. Most of the times these sellers are selling a multitude of sometimes, diversified set of products that they would have purchased from larger markets; they face a lack of cash credit system or inventory credit facilities [1-3,9]. These low income individuals with limited means at most times pool in their personal resources to gather money to start the business and run it[10]. There is dearth of working capital and investment capital. However, in spite of this, these sellers have been seen offering products and services at credit to their customers.

\subsection{Weak networks-}

While we discuss the network being weak, it refers to value chains that could be made available to sellers by middlemen, wholesalers or large retailers from whom these sellers will be purchasing their products [15]. For instance, if a seller of locally or homemade biscuits, spice powders etc would have been able to gather value chains, he could look at stacking up an inventory of other product ranges that the large retailer would be having and this would give a depth of the customers shopping basket and a bigger chunk of profits for the seller, while for the customer he can purchase all his household needs at one seller. This value chain and ecosystem advantage is not available for the sellers in subsistence markets.

\subsection{Low productivity-}

By productivity we mean the relationship between inputs and output, while for a large retailer he would be able to get maximum productivity from his equation of inputs to output, for a street vendor, his inputs would outweigh his final output and he is most times working on thin margins and productivity. He would need to scout for good quality products, get it at the right prices, there will not be one regular supplier, no credit facilities, most of this purchases would be against cash so if he is giving credit to this customers, at most times this would again erase his margins and profits if we account for the opportunity costs associated with doing business with his customers on credit.

\subsection{Poor working conditions-}

From power cuts to water shortages to lack of basic sanitation facilities, most subsistence market consumers and sellers grapple with poor working and living conditions in their lives. This in turn also affects the quality of their lives. From the point of view of product development to after sales scenario these poor working conditions highly affect products that are purchased, the places from where they are purchased and when and how and from whom they are purchased.

\subsection{Supply constraints-}

Lack of buyers' credit facilities from suppliers, wholesalers or lending institutions and the absence of value chains, "ecosystems" are all interlinked $[15,16]$. By and large sellers in subsistence markets coexist with other sellers by selling products and services which are critical and price variations are acceptable only within certain limits. This being the case sellers faces a lot of non credit related barriers such as supply to try and procure their goods at the lowest cost possible. There is no one regular supplier and wholesaler that they can tie up with because of issues related to volumes, credit terms, inventory purchase abilities and a host of other economic constraints making supply a major issue. The street vendor or seller buys his products and services from a diverse range of wholesalers, large retailers or manufacturer representatives whichever suits his product profile and capital flows best.

\subsection{Marketing constraints-}

Subsistence consumers have a unique characteristic of relying very heavily on word of mouth communication and one to one social interactions. For a marketer this holds a lot of promise because he can rely heavily on certain media and vehicles to carry his message forward. But for a seller in the subsistence market, he cannot really spend a lot of time and money on any type of marketing efforts. The reason being his products and services sell mostly by w-o-m and one to one interactions and a close knit bond with the few customers who would in turn attract other buyers. Even then, a small discount or a "free" promotion offered by any other fellow seller will severely affect other sellers if they cannot match up with any such similar offers.

\subsection{Socio-economic constraints-}

Low education and literacy levels, lack of basic amenities', poor or no access to developed logistic networks, poor sanitation, lack of resources to mobilise adequate transportation and storage facilities are only some of the socioeconomic constraints of the seller in subsistence markets. 
Buyers and most of the sellers in subsistence markets have low education, low standards of living and most of their incomes are spent on purchasing sustenance products and services, needless to say, some smart marketers and large business corporations like Reliance Communications in India during 2003, made available mobile phone connections with handsets at 500 INR thus sphere heading a movement of low cost mobile handsets being made available to the BOP customers as well [1-2, 17]. Within the realm of socio economic constraints, sellers in subsistence markets have to scout for products that they can purchase at lower costs so they could sell it to their customers at a considerable mark-up. There is a constant interaction with other sellers and buyers in these markets, this helps them to leverage their and others knowledge on products and services.

\section{SUCCESSFUL PRACTICES OF SUBSISTENCE VENDORS :}

Most BOP markets are characterized by a very close knit connection of interdependence between sellers and buyers in these resource poor settings. And since most come from a similar socio economic background and share similar adversities, many buyers would have experience as a seller at some point or other. Their interactions thus would be influenced by a deep empathy for each other. For firms and researchers to understand the successful practices have twin advantages. One is to develop a bottom up approach to understanding how to serve and succeed in these markets. Two, is to pave the way to enable the adoption of these successful and indigenous practices in other niche markets if possible.

Sellers or vendors in subsistence markets have been in this business of buying and reselling or in some cases of manufacturing themselves at a very small scale and selling since a very long time. Certain vendors in some markets have become monopolies for their unique offerings and other seller shave not been able to create a dent in their sales. These few vendor shave become brands by themselves today or they have created their brand identities. If you look closely you will find them in markets around you. It could be a local fried snacks or papad pickle seller in your neighbourhood. It could be the street corner barber who has today managed to set up his own small self styled saloon which is even now thronged with customers. There are certain unique indigenous practices that have made them stand out.

4.1. Network- One of the most significant pinup points of street vendors also termed as sellers in subsistence markets is the very strong social networks they have built around them. Subsistence markets have a unique characteristic of being a close knit market between buyers and sellers. Every small transaction involves frequent and detailed one to one interaction and exchange of information of general nature. The interactions are such deeply set that product and service purchase seems only a secondary non important criterion. These strong social networks make it impossible for any other seller to gain entry into any particular seller's customer base. These marketplaces having high one to one interaction between small neighbourhood sellers and local consumers show the significance of combining economic and social relationships among players in the marketplace. HLL, in India has tried and succeeded in this winning practice of building an economic and socially networked selling space in rural and semi urban centres through its shakti programs which partnered with local womenfolk to partner and sell its products and services as micro franchisers [1-3,18]. In fact, micro franchising takes this vast socio economic networking to another level to strategise it into a win -win situation for both the players.

4.2. Providing Value Propositions- certain product suites in subsistence markets run exclusively due to their specific need in that BOP category. For instance, a local key making, lock repairing services, shoe making to suit specific target customer needs, buying set of products and disassembling and selling parts of it which might be the requirement in these markets. There are numerous such examples of products and services in markets around us, providers of which have become brands in themselves. Their services might be used not just by subsistence buyers but customers from other markets who have higher standards of living would be attracted to or use these services. The value proposition that it would provide to these buyers is what makes the seller successful. Be it in any marketplace if the customers do not perceive value, the product or a service sale becomes very negligible. Especially, in subsistence markets buyers have very little manoeuvrability in terms of price variations or the product fulfilling their need; hence they are very keen on cashing in the value box within the given available constraints. The value chain in a subsistence marketplace- 


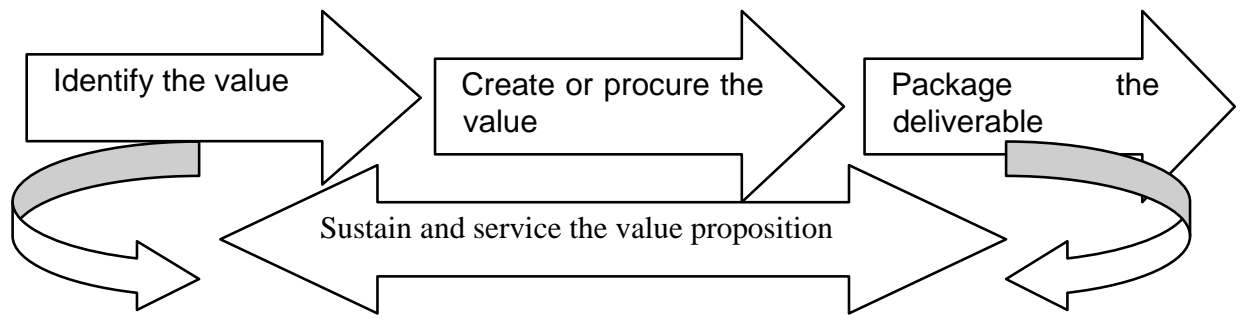

Fig. 1 : The value chain in a subsistence marketplace.

For sellers in subsistence market sit is very essential that they find a value or critical want that needs to be satisfied in their products and services. The buyers here have limited financial resources and limited literacy, within these constraints they have to scout for products and services that will fulfil their need and provide value for the money that they spend for the product or service. Hence, the seller has to identify the critical value that he can provide within a price parameter, create or procure that value product/service at the least cost available, package the deliverable and ensure that this value chain is an ongoing continuous exercise in all products and services that he is selling. Subsistence markets sellers increase consumer acceptance by giving low cost diversified critical products and services which could not be got elsewhere.

4.3. Effective Word of Mouth- A continuum of the networked strength that sellers in these markets strategize on the one to one interactions to act as promotional programs for them. In the absence of resources to spend on promotions buyers themselves act as carriers of word of mouth publicity and promotion for the sellers. This is due to the fact that the buyer seller relationship here transcends beyond just the economic exchange. The seller treats the buyer more or less as a family member and vice versa. Even though the seller lacks purchase credit himself, he is always willing to give credit to his buyers which forge their bond forward. Lot of sellers function on daily, weekly and monthly payment schemes for their buyers much before large corporations started the equated Monthly Instalment schemes. For the part of buyers this ties them to the seller for long periods. The seller on his part is willing to take up the risk of the dues going bad. The grameena bank concept, that was started if Bangladesh by Mohammed Yunus and many other such cons pets that have been enforced are affective due to the high level of word of mouth promotion [19, 22]. In Dakshin Kannda district microfinance schemes, agricultural product schemes have been very successfully adapted very willingly due to effective word of mouth publicity. Human psychology is such that we are willing to take up a suggestion by some kith and kin more easily than by a forum of media publicity.

4.4. Adaptivity- Subsistence markets are typically not large homogenous markets, every urban, semi urban or rural centre might be characterized by its own set of local customs, needs and circumstances. One distinct product or service offering cannot be tailored to the entire nations market. Sellers in these markets are very successful at tailoring products and services to their immediate buyer community. A lot of Rajashtani people set shop selling ladies ethnic wear materials and ready wear in street sides and they are able to tailor their products to the place they are currently selling in. It is very critical to identify with the needs and requirements of the customers rather than spend crores of rupees in advertising unwanted and unnecessary products services that is not tuned in to local cultures. Also since there is socio economic interaction to a very high level it is easy for sellers to understand the nerve of the buyer community. It helps the sellers to pick up suitable businesses and product suites.

4.5. Critical Need Identification- As a continuation to providing value, seller has to identify critical needs of the buyers. Since most customers in subsistence markets have low incomes and are able to purchase only essential goods and services, a seller to be successful has to package his product to fill the want of a critical need. As Reliance Telecom did in India, they recreated a mobile handset which could be purchased at a minimal price and payment in instalments also ensuring that the critical want of a subsistence buyer for mobile connectivity could be converted into a need overnight. Subsistence buyers realised that this service was affordable to them now. So also with water purifier business in India. Many sellers in BoP markets have used this critical 'want' identification and sold predicts or services by making them a 'need' for the buyers and providing it on credit terms or in easy purchase methods. 
4.6. Localized Productions or sourcing- Primarily because of the costs associated with procuring goods and services, sellers try and procure goods and services locally or try to procure it from the buyers themselves. The buyers in some cases might be providing the raw materials for the finished goods. This can also hold good for sellers in the industry of handicrafts. Most of the artisans or handicrafts are manufactured in BOP markets the resources are procured locally and sellers go through strenuous efforts to create beautiful crafts, handloom products, potteries etc. Even in the case of the street food industry the raw materials for manufacturing the finished goods, be it pickles, papads, street fast foods are all procured locally at the source of sale. The buyers in these cases could be from the BOP markets and from the across other niche categories, even high end customers, especially in the case of handicrafts etc. Also in India there is the transitional informal market called, sandy bazaars, "santhes" where buyers and seller meet once a week to exchange goods and service for a price. Bargaining is a characteristic of subsistence markets in India. In these market sells the products or services are locally produced or procured. In certain cases the buyers also may be sellers and vice versa. It has its own set of regular customers predominantly who transact heavily on the one to one networking created over the years. There are a lot of free moving customers also who need not necessarily be from the subsistence class of customers.

4.7. Proximity and flexible terms of purchase- The most interesting aspect of subsistence markets we believe it its ability to give very flexible terms of purchase or resale for its buyers. The sellers are at very close proximity to the buyers and the seller is willing to offer credit- short term and long term, buy back products, resell buyers goods if required and a host of other specialized services which has made them successful at their trade. For subsistence customers who come from low income groups and have limited means to socialise, these informal arrangements and relationships create a deeper bonding with the customer. This is by far not possible for large business corporations and retailers, but many are trying to tie up with local sellers and create this bon homie.

\section{CONCLUSION :}

The base of the pyramid markets account for close to 3.5 billion adults of the world population and they have managed to exist successfully down the years with their own set of sellers who have exhibited several indigenous success practices as discussed above. After C.K. Prahalad published several works on the strength of the BOP markets in 2005 several large corporations have seen value in strategizing to strengthen their presence in these markets [22]. This obviously requires close cooperation with existing sellers in these markets and adequate product changes to make it suitable in price and value terms to buyers in subsistence markets. A profound knowledge and deeper understanding of the rural and semi urban and also of some subsistence markets in cities would enable large corporations and big wholesalers to try and tap these markets. Be it exercise such an $\mathrm{s}$ the ubiquitous sachets of shampoos, hair oils, hand washes that in now seen in every nook and corner shop. The success will be seen only when an attempt is made to educate the low literacy buyer on the need for the product. Penetrating these new markets is a challenge not just in terms of giving product access but in giving enough education to the targeted class and reaching them in a medium they have access to and believe.

\section{REFERENCES :}

[1] Viswanathan, M., Sridharan, S., \& Ritchie, R. (2010). Understanding consumption and entrepreneurship in subsistence marketplaces. Journal of Business Research, 63(6), 570-581.

[2] Bhowmik, S. K. (2005). Street vendors in Asia: a review. Economic and political weekly, 22562264.

[3]Bayat, A. (1997). Un-civil society: The politics of the 'informal people'. Third World Quarterly, 18(1), 53-72.

[4] Bird, Frederick and Stewart W. Herman. 2004. International Business and the Challenges of Poverty in the Developing World. Case Studies on Global Responsibilities and Practices. New York: Palgrave Macmillan, p. 247. 
[5] Bornstein, David. 2004. How to Change the World. Social Entrepreneurs and the Power of New Ideas. New York: Oxford University Press, p. 320.

[6] Blum, E. 1993. Making Biodiversity Conservation Profitable: A Case Study of the Merck/INBio Agreement. Environment 35(4), 16-20, 38-45. http://www.ciesin.org/ docs/002-270/002270.html accessed on 16/05/2017.

[7] Christensen, L. J. (2008). Chapter Eight Alleviating Poverty Using Microfranchising Models: Case Studies and a Critique. Alleviating poverty through business strategy, 149.

[8] Christensen, L. J., Parsons, H., \& Fairbourne, J. (2010). Building entrepreneurship in subsistence markets: Microfranchising as an employment incubator. Journal of Business Research, 63(6), 595-601.

[9] Cross, J. (2000). Street vendors, and postmodernity: conflict and compromise in the global economy. International Journal of Sociology and Social Policy, 20(1/2), 29-51.

[10] Cross, J. C. (1998). The informal sector. Encyclopedia of Political Economy. Routledge, London and New York.

[11] Cross, J. C. (1998). Informal politics: Street vendors and the state in Mexico City. Stanford University Press.

[12] Crossa, V. (2009). Resisting the entrepreneurial city: street vendors' struggle in Mexico City's historic center. International Journal of Urban and Regional research, 33(1), 43-63.

[13] Dawson, R. J., \& Canet, C. (1991). International activities in street foods. Food Control, 2(3), 135-139.

[14] Fairbourne, J. S. (2006). Microfranchising: a new tool for creating economic self-reliance. Journal of Microfinance/ESR Review, 8(1), 18-23.

[15] Harney, N. (2006). Rumour, migrants, and the informal economies of Naples, Italy. International Journal of sociology and social policy, 26(9/10), 374-384.

[16] Lues, J. F., Rasephei, M. R., Venter, P., \& Theron, M. M. (2006). Assessing food safety and associated food handling practices in street food vending. International Journal of Environmental Health Research, 16(5), 319-328

[17] Magleby, K. (2007). Microfranchise business models. MicroFranchising-Creating Wealth at the Bottom of the Pyramid, Cheltenham: Edward Elgar, 133-148.

[18] Muyanja, C., Nayiga, L., Brenda, N., \& Nasinyama, G. (2011). Practices, knowledge and risk factors of street food vendors in Uganda. Food Control, 22(10), 1551-1558.

[19] Muzaffar, A. T., Huq, I., \& Mallik, B. A. (2009). Entrepreneurs of the streets: an analytical work on the street food vendors of Dhaka city. International journal of Business and Management, 4(2), 80 .

[20] Morrison, T., Conaway, W. A., Borden, G. A., \& Koehler, H. (1994). Kiss, bow, or shake hands: How to do business in sixty countries. Holbrook, Mass.: Adams Media Corporation.

[21] Nakata, C. (2012). From the special issue editor: Creating new products and services for and with the base of the pyramid. Journal of Product Innovation Management, 29(1), 3-5.

[22] Weidner, K. L., Rosa, J. A., \& Viswanathan, M. (2010). Marketing to subsistence consumers: Lessons from practice. Journal of Business Research, 63(6), 559-569. 